\title{
Serum increase and liver overexpression of carbohydrate 19.9 antigen in patients with genetic haemochromatosis
}

\author{
Y M Deugnier, A-F Rabot, D Guyader, R Moirand, B Turlin, E Boucher, P Lebert, \\ P Brissot
}

\begin{abstract}
CA 19.9 antigen is mainly secreted by biliary and pancreatic duct cells. Its metabolism could be modified in genetic haemochromatosis by iron accumulation within these cells. Therefore, CA 19.9 was assayed in the serum samples of 84 patients with genetic haemochromatosis before and after iron depletion and immunolocalised in the liver of 24 untreated genetic haemochromatosis cases. The study showed that serum CA $19.9(\mathbf{N}<37$ IU/I) was increased (SD) before treatment $(41.2$ (34)) when compared with after the venesection period (16 (12)), and correlated, before treatment, with the amount of iron excess, transaminases, fibrosis, and biliary iron deposits. Hepatic CA 19.9 was located within the cytoplasm of bile duct and cholangiolar cells. In conclusion, this study shows that a mild, reversible, and non-specific increase in serum CA 19.9 is common in genetic haemochromatosis patients and shows that this increase is related to iron excess, directly or through associated liver damage. The unexplained finding of a mild increase in serum CA 19.9 should lead, in a patient with no diagnosis, to the search for liver iron overload, and, in a patient with untreated genetic haemochromatosis, not to further diagnostic procedures unless this finding persists after completion of the venesection treatment.

(Gut 1994; 35: 1107-1111)
\end{abstract}

CA 19.9 antigen, a mucine ${ }^{12}$ containing sialylated lacto- $N$-fucopentaoseII, ${ }^{3-7}$ is widely used as a marker for pancreas cancer. ${ }^{8-14}$ A large number of reports, however, have focused on the increase of serum CA 19.9 in other malignancies as well as in non-malignant conditions, ${ }^{15-19}$ especially chronic and acute liver diseases. ${ }^{41720-24}$ The liver is the main site for CA 19.9 metabolism. Indeed, biliary cells are responsible for CA 19.9 synthesis and excretion into blood and bile, 2225 and hepatocytes participate in the catabolism of desialylated CA 19.9.2627 As iron deposits within both biliary cells and hepatocytes in patients with genetic haemochromatosis, ${ }^{28}$ the question was raised of putative disturbances of CA 19.9 metabolism in genetic haemochromatosis, more especially as some genetic haemochromatosis patients referred to our unit presented with an unexplained increase in serum CA 19.9. A study was undertaken in an attempt (a) to determine serum CA 19.9 in patients with untreated and treated genetic haemochromatosis and (b) to immunolocalise CA 19.9 in the liver from untreated patients.

\section{Patients and methods}

INCLUSION CRITERIA

Eighty one patients with genetic haemochromatosis diagnosed during the period 1990-92 were studied. A positive diagnosis of genetic haemochromatosis was established by (a) absence of anaemia, haemolytic disease, regular transfusions or longterm intake of iron containing drugs, (b) classic clinical, biological, ${ }^{29}$ and pathological ${ }^{28}$ signs of genetic haemochromatosis, and (c) a hepatic iron concentration to age ratio (=hepatic iron index) $>2^{3031}$ or histological iron score to age ratio greater than 0.2 , or both. ${ }^{32}$ All patients had a liver biopsy for assessment of fibrosis and iron excess and an ultrasound examination to exclude a space occupying lesion.

\section{BIOCLINICAL DATA}

The following data were recorded at the time of both genetic haemochromatosis diagnosis and de-ironation: age, sex, diabetes, chronic alcoholism (>80 g/day for more than 10 years), serum iron $(\mathrm{N}<22 \mu \mathrm{mol} / \mathrm{l}$ in men and $<20$ in women), transferrin saturation $(\mathrm{N}<40 \%)$, serum ferritin $(\mathrm{N}<400 \mu \mathrm{g} / 1$ in men and $\angle 300$ in women), serum CA 19.9 (enzyme immunoassay EIA-CA 19.9, CIS bio international, BP32, 91192 Gif sur Yvette, France $\mathrm{N}<37$ IU/1), alanine aminotransferase (ALT $\mathrm{N}<50 \mathrm{IU} /$ ), alkaline phosphatase (APT $\mathrm{N}<111$ IU/1), 5' nucleotidase $(\mathrm{N}<9$ IU/l), $\gamma$-glutamyltransferase (GGT) $(\mathrm{N}<43 \mathrm{IU} / \mathrm{l})$, total bilirubin $(\mathrm{N}<17 \mu \mathrm{mol} / \mathrm{l})$, and prothrombin time $(\mathrm{N}>80 \%)$. De-ironation was defined using the total amount of weekly removed iron expressed as grams $(\mathrm{g})$ necessary to return iron stores to low normal concentrations (serum ferritin lower than $50 \mu \mathrm{g} / \mathrm{l}$ in all but one patient).

PATHOLOGICAL DATA

Liver biopsy samples were fixed in formalin and embedded in paraffin wax. Sections were cut at $4 \mu \mathrm{m}$ and stained using haematoxylin-

\author{
Correspondence to: \\ Dr Y M Deugnier, Clinique \\ Centre Hospitalier Régional \\ et Universitaire, \\ Pontchaillou, rue Henri le \\ Guilloux, 35033 Rennes, \\ Accepted for publication \\ Accepted for publicati
17 November 1993 \\ du Foie and INSI
U49,
Y M Deugnier
A-F Rabot
D Guyader
R Moirand
E Boucher
P Brissot
Laboratoire
d'Anatomie et de
Cytologie
Pathologiques,
B Turlin
and Laboratoire
d'Hormonologie-
Enzymologie, Ce \\ Hospitalier Régiona \\ and Universitaire, \\ France \\ P Lebert
}




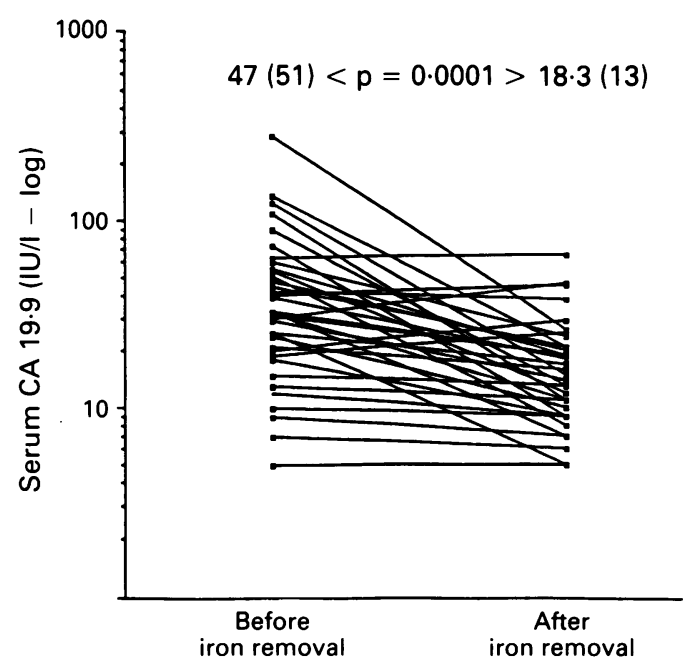

Figure 1: Serum CA 19.9 (IU/ - N<37-log) before and after iron removal in 37 patients with genetic haemochromatosis. Mean (SD).

eosin-saffron, Gordon Sweet (or Sirius red) for reticulin framework, Masson's trichrome for connective tissue, and Perls' Prussian blue reaction for iron. The following data were studied: (a) histological total iron score (range: $0-60$ ) as previously reported ${ }^{28}$; (b) fibrosis stage according to a five grade scale (F0: no fibrosis, F1: non-extensive portal fibrosis, F2: non-bridging extensive portal fibrosis, F3: bridging fibrosis without cirrhosis, F4: cirrhosis); (c) liver iron concentration ( $N<36$ $\mu \mathrm{mol} / \mathrm{g}$ ) according to Barry and Sherlock. ${ }^{33} 34$ Immunolocalisation of CA 19.9 was made using the avidin-biotine-complex method (HistoCIS CA 19.9, CIS bio international). Positive controls consisted of normal and cirrhotic non-haemochromatotic livers, and colonic and biliary cancer tissues. For negative controls, primary antibody was omitted. From 81 liver biopsy specimens, 76 were available for semiquantitative assessment of iron, 70 for liver iron concentration determination, and 24 for CA 19.9 immunolocalisation.

STATISTICAL ASSESSMENT

Statistical assessment was made with Spearman's test for correlation between quantitative data, Wilcoxon's test for comparison

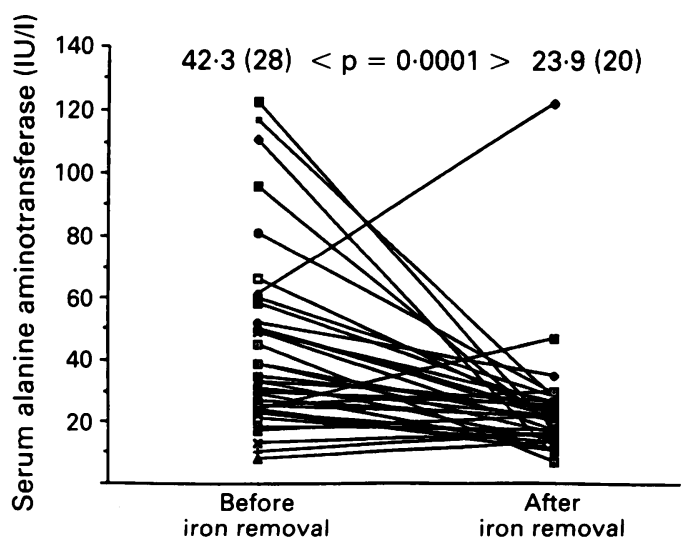

Figure 2: Serum alanine aminotransferase (IU/ $-N<50)$ before and after iron removal in 32 patients with genetic haemochromatosis. Mean (SD). between paired or unpaired quantitative data, and $\chi^{2}$ and Krushal-Wallis for comparison of qualitative data. Difference was considered as significant for $\mathrm{p}<0.05$.

\section{Results}

In the whole population, serum CA 19.9 ranged from 5 to $464 \mathrm{IU} / 1$ (mean 51.5 (74)) and was greater than the upper limit of normal in $38 \%$ of patients. When considering treated patients only $(n=37)$, a significant $(p=0.0001)$ decrease in serum CA 19.9 was found between before treatment (47 (51) range: $5-284)$ and after treatment (18.3 (13) range: 5-66) values (Fig 1). All but one patient with abnormal (>37 IU/l) pretreatment serum CA 19.9 had a normal concentration after de-ironation. From six patients in whom a serum CA 19.9 decrease was not seen, one non-cirrhotic man presented with an unchanged abnormal serum CA 19.9 ( 63 before and 66 after treatment), one with a significant and unexplained increase after the venesection programme (30 to 46 ), and four with a slight increase within the normal range (19 to 25,19 to 25,20 to 29 , and 20 to 29).

When considering all patients as well as treated patients only, the initial serum CA 19.9 was significantly correlated with age $(p=0.02)$, iron store assessed on serum ferritin $(p=0.0001)$, liver iron concentration $(p=0.003)$, histological total iron score $(p=0.0001)$, and removed iron $(p=0.0006)$, with serum ALT $(p=0.0001)$, GGT $(p=0.006)$, and alkaline phosphatase $(p=0.0005)$ and to fibrosis stage $(p=0.0001)$. Sex, diabetes, and history of chronic alcoholism did not modify these figures.

Pretreatment serum CA 19.9 was not significantly different in alcoholics $(66 \cdot 4(17 \cdot 6)$ range: 8-464) when compared with nonalcoholics (43.2 (8.1) range: 5-390) and decreased after venesection in both groups. Otherwise, it was of note that a strong correlation did exist between iron store and serum ALT ( $p=0.0001)$, alkaline phosphatase $(p=0.0001)$, and GGT $(p=0.001)$. In treated patients $(n=37)$, a significant decrease in serum iron, transferrin saturation, ferritin, ALT (Fig 2), and total bilirubin was seen when comparing before and after treatment data (Table).

All genetic haemochromatosis liver biopsy specimens studied $(n=24)$ were positive for CA 19.9. In all cases, positivity was located within the cytoplasm of bile duct cells: iron overloaded ducts presented with an intense black positivity that differed from the faint staining of unloaded ducts. In addition, in fibrotic haemochromatotic livers, a noticeable positivity was seen in periportal cholangiolar cells (Fig 3). A correlation ( $p=0 \cdot 02)$ was found between the presence of iron deposits within biliary cells and the increase of serum CA 19.9 (biliary iron $(+): 99.6(109) v$ biliary iron $(-)$ : $21 \cdot 7$ (13.1) (Fig 4)). In normal control livers, bile ducts were faintly and inconsistently stained and no positivity was found in periportal areas. In non-genetic haemochromatosis 
Biological data in treated patients before and after venesection treatment

\begin{tabular}{lccc}
\hline & Before treatment & After treatment & Number tested \\
\hline Serum CA $19.9^{\star}(\mathrm{N}<37 \mathrm{IU} / 1)$ & $47(51)(5-284)$ & $18 \cdot 3(13)(5-66)$ & $37 / 37$ \\
Serum iron ${ }^{\star}(\mathrm{N}<22 \mu \mathrm{mol} / 1)$ & $37(9)(15-53)$ & $14(7)(5-37)$ & $36 / 36$ \\
Transferrin saturation $(\mathrm{N}<40 \%)$ & $68(18)(26-95)$ & $19 \cdot 5(9 \cdot 5)(7-41)$ & $36 / 36$ \\
Serum ferritin $(\mathrm{N}<400 \mu \mathrm{g} / \mathrm{l})$ & $1650(1617)(126-7125)$ & $38(33)(7-175)$ & $37 / 37$ \\
Alanine aminotransferaset $(\mathrm{N}<50 \mathrm{IU} / \mathrm{l})$ & $42 \cdot 3(28 \cdot 4)(8-123)$ & $24(19 \cdot 6)(9-122)$ & $37 / 32$ \\
Alkaline phosphatase $(\mathrm{N}<110 \mathrm{IU} / \mathrm{l})$ & $86 \cdot 6(35 \cdot 2)(40-198)$ & $77(25 \cdot 7)(40-139)$ & $36 / 32$ \\
$5^{\prime}$ nucleotidase $(\mathrm{N}<9 \mathrm{IU} / \mathrm{l})$ & $3 \cdot 8(2)(0 \cdot 7-9.3)$ & $2 \cdot 8(1)(0.8-4.5)$ & $27 / 14$ \\
$\gamma$ glutamyltransferase $(\mathrm{N}<43 \mathrm{IU} / \mathrm{l})$ & $39 \cdot 3(47 \cdot 5)(11-296)$ & $36(30 \cdot 3)(7-128)$ & $36 / 32$ \\
Total bilirubin $\neq(\mathrm{N}<17 \mu \mathrm{mol} / \mathrm{l})$ & $12 \cdot 6(7 \cdot 4)(3-34)$ & $9(6)(3-25)$ & $28 / 27$ \\
Prothrombin time $(\mathrm{N}>80 \%)$ & $93(10)(66-100)$ & $93(9)(72-100)$ & $37 / 15$ \\
\hline
\end{tabular}

Results are expressed as mean (SD) (range). Significance difference before and after treatment: ${ }^{\star} \mathrm{p}=0.00001,+\mathrm{p}=0.0003$, $\neq \mathrm{p}=0.015$ (Wilcoxon's test).

cirrhotic livers, bile duct cells exhibited a slight staining - much less intense than in haemochromatotic livers - while periportal cholangiolar cells presented with a noticeable positivity as found in iron overloaded cases. Negative controls from genetic haemochromatosis patients did not exhibit any staining.
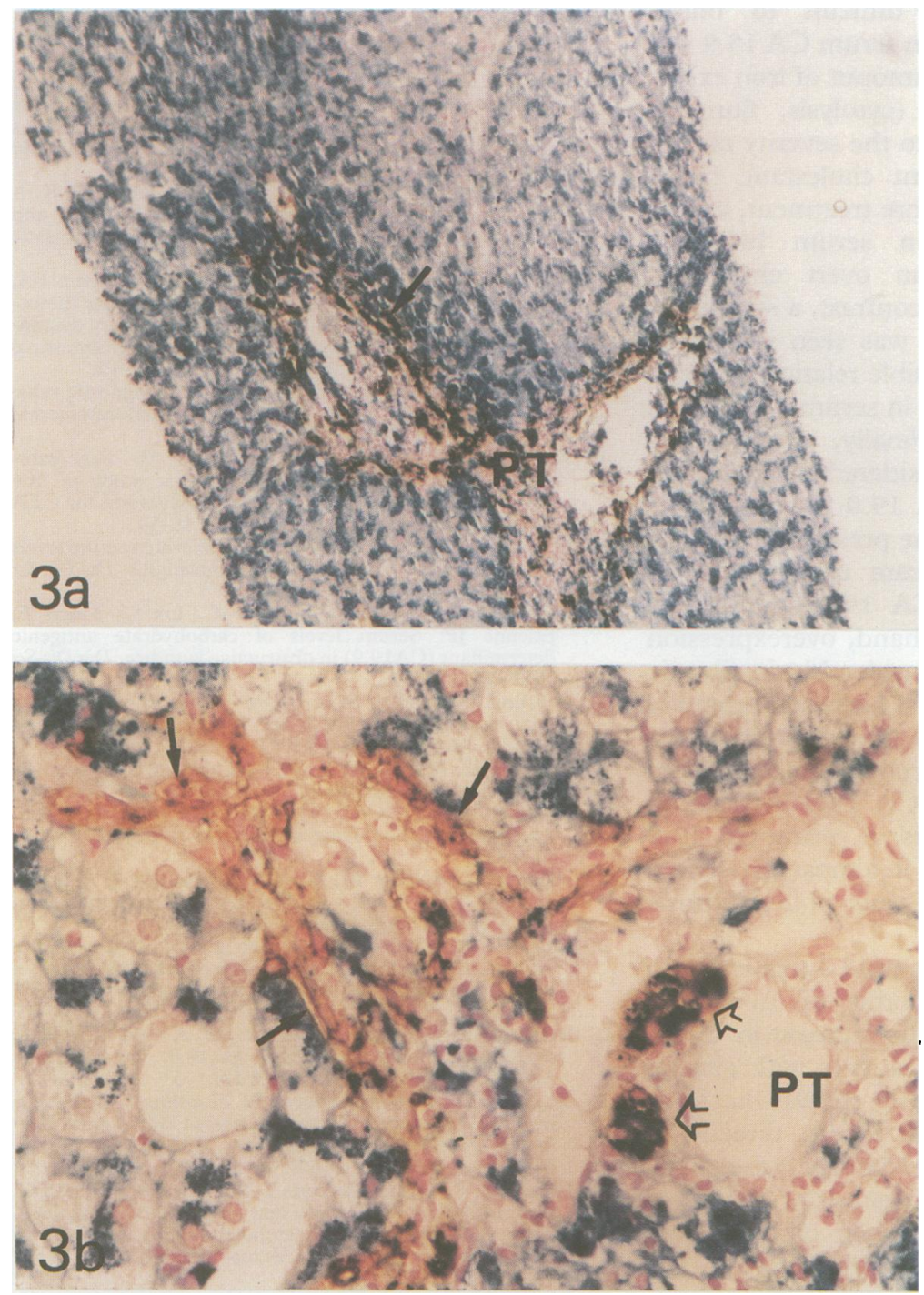

Figure 3: Immunolocalisation of hepatic CA 19.9 in genetic haemochromatosis (HistoCIS CA 19.9-Perls counterstaining - PT: portal tract): intense staining of bile duct (arrowhead) and cholangiolar (arrow) cells, in a heavily iron overloaded liver with stage 2 fibrosis (a, original magnification $\times 16$ ) and in a cirrhotic haemochromatotic liver (b, original magnification $\times 40)$.

\section{Discussion}

This study shows that serum CA 19.9 is increased in patients with genetic haemochromatosis, is correlated not only with the amount of liver and biliary iron but also with liver function tests abnormalities and the presence of fibrosis, and also decreases after completion of the venesection programme. It was also shown that hepatic CA 19.9 is overexpressed within iron overloaded bile duct cells in genetic haemochromatosis. The decrease in serum CA 19.9 after de-ironation implies that iron overload is responsible for changes in CA 19.9 metabolism. No definite conclusion can be drawn, however, about the mechanism of these disturbances, which may be either directly related to iron or secondary to iron induced liver damage.

A role of pancreas iron overload seems unlikely. Indeed, no difference was found in serum CA 19.9 according to the presence or absence of diabetes. The role of liver is more probable. Indeed, biliary cells participate in CA 19.9 metabolism. CA 19.9 synthesis is located in these cells ${ }^{22} 25$ and entails a sialyl transferase activity, ${ }^{535}$ which is increased in inflammatory liver process. ${ }^{35} 36$ Mild lymphocytic and histiocytic liver inflammation and sideronecrosis have been described in genetic haemochromatosis. ${ }^{28}$ Therefore, an increase in sialyl transferase activity may be suggested as a factor of increase in CA 19.9 biliary synthesis.

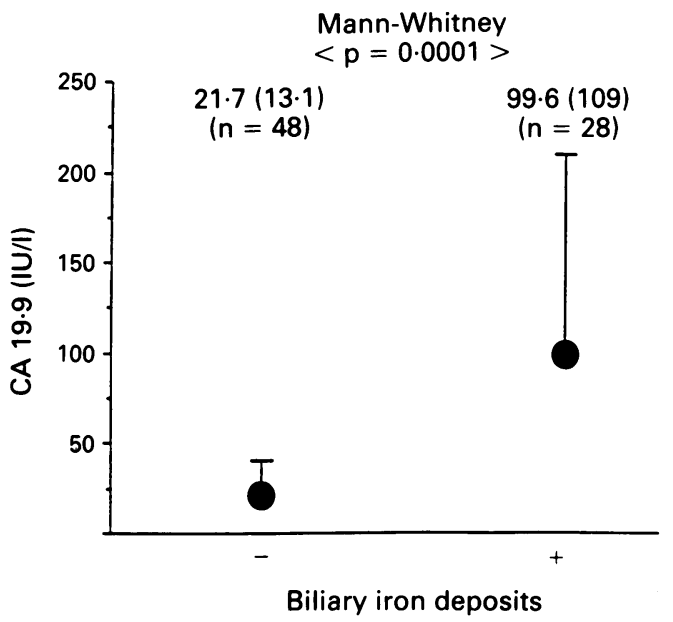

Figure 4: Serum CA 19.9 antigen (IU/l) according to the presence $(+)$ or absence $(-)$ of iron deposits within bile duct cells. Mean (SD). 
Moreover, CA 19.9 catabolism is, in part, carried out in biliary cells through a nonsaturable transfer process into bile. ${ }^{27}$ This process may be impaired in the iron overloaded biliary cell as it has been shown for other excretion pathways in genetic haemochromatosis. ${ }^{37}$ The findings of a correlation between serum CA 19.9 and biliary iron deposition and of a positivity of CA 19.9 antigen within bile ducts much stronger in haemochromatosis than in non-genetic haemochromatosis cirrhosis may suggest such an impairment. In addition, circulating serum CA 19.9 is cleared from blood after desialylation through a specific binding by asialoglycoprotein receptors. ${ }^{26} 27$ This receptor activity is known to be decreased in most of the acute and chronic liver diseases even in the absence of cirrhosis. ${ }^{38-40}$ Therefore, it can be suggested that, by decreasing the number or activity of these receptors, or both iron overload could be responsible for an increase in serum CA 19.9 through an impairment of asialoglycoprotein catabolism.

Besides a putative role of iron in itself, a role of iron related liver damage may be discussed. Such a distinction is difficult to make, however, as the increase in serum CA 19.9 was correlated both with the amount of iron excess and with liver damage (cytolysis, fibrosis), which is directly related to the severity of iron overload. ${ }^{28}$ No significant cholestatic figure was found in patients before treatment, except for a mild increase in serum bilirubin. Therefore, a role of an overt cholestatic syndrome is unlikely. In contrast, a significant decrease in serum ALT was seen in treated patients suggesting a possible relation between cytolysis and the increase in serum CA 19.9 as previously reported. ${ }^{41}$ Finally, whatever its aetiology, cirrhosis is considered as a common cause of mild serum CA 19.9 increase. ${ }^{40-24}$ This was confirmed by the present data as, on the one hand, a significant correlation was found between serum CA 19.9 and fibrosis stage, and, on the other hand, overexpression of liver CA 19.9 was considerable in fibrotic and cirrhotic genetic haemochromatosis patients. In contrast with the commonly held view, however, fibrosis process does not seem to participate in serum CA 19.9 increase in genetic haemochromatosis, as serum CA 19.9 decreased after treatment in almost all patients despite the absence or presence of liver fibrosis or cirrhosis.

This study shows that a mild - that is, up to four times the upper limit of normal reversible, and non-specific increase in serum CA 19.9 is common in patients with genetic haemochromatosis. It also shows that this increase is related to iron excess, directly or through associated liver damage, especially cytolysis but not overt cholestasis or fibrosis as commonly reported in other chronic liver diseases. From a practical point of view, the unexplained finding of a mild increase in serum CA 19.9 should lead, in a patient with no diagnosis, to the search for liver iron overload and, in a patient with untreated genetic haemochromatosis, not to further diagnostic procedures unless this finding persists after completion of the venesection treatment.

The authors are grateful to Danièle le Quilleuc, Jean-Yves Robert, and Rémi Trinquart for their excellent technical assistance. This work was supported by grants from the Association pour la Recherche pour le Cancer.

This study was presented at the American Association for the Study of Lur pisease held in Chicago on 31 . November 1992 (Hepatology 1992; 16: 114A).

1 Kalthoff H, Kreiker C, Schmiegel WH, Greten H, Thiele HG. Characterization of CA19.9 bearing mucins as physiological exocrine pancreatic secretion products. Cancer Res 1986; 46: 3605-7.

2 Magnani JL, Steplewski Z, Koprowski H, Ginsburg V. Identification of the gastrointestinal and pancreatic cancer-associated antigen detected by monoclonal antibody 19.9 in the sera of patients as a mucin. Cancer Res 1983; 43: 5489-92.

3 Appert HE. Composition and production of pancreatic tumor related antigens. Int 7 Pancreatol 1990; 6: 13-23.

4 Del Villano BC, Zurawski VR The carbohydrate antigenic determinant 19.9 (CA19.9): a monoclonal antibody defined tumor marker. In: Liss AR, ed. Immunodiagnostics. New York, 1983: 269-82.

5 Hansson GC, Zopf D. Biosynthesis of the cancer-associated sialyl-le(a) antigen. $\mathcal{F}$ Biol Chem 1985; 260: 9388-92.

6 Magnani JL, Nilsson B, Brockhaus $\mathrm{M}$, et al. A monoclonal antibody-defined antigen associated with gastrointestinal cancer is a ganglioside containing sialylated lactoN-fucopentaoseII. $尹$ Biol Chem 1982; 257: 14365-9.

7 Itzkowitz SH, Kim YS. New carbohydrate tumor markers. Gastroenterology 1986; 90: 491-3.

8 Safi F, Beger HG, Bittner R, Buchler M, Krautzberger W. CA19.9 and pancreatic adenocarcinoma. Cancer 1986; 57: $779-83$.

9 Safi F, Roscher R, Beger HG. Tumor markers in pancreatic cancer. Sensitivity and specificity of CA19.9. Hepatogastroenterology 1989; 36: 419-23.

10 Satake K, Kanazawa G, Kho I, Chung Y, Umeyama K. Evaluation of serum pancreatic enzymes, carbohydrate antigen 19.9, and carcinoembryonic antigen in various pancreatic diseases. $A m \mathcal{f}$ Gastroenterol 1985; 80: 630-6.

11 Satake K, Kanazawa G, Kho I, Chung Y, Umeyama K. A clinical evaluation of carbohydrate antigen 19.9 and carcinoembryonic antigen in patients with pancreatic carcinoma. ₹ Surg Oncol 1985; 29: 15-21.

12 Staab HJ, Brummendorf T, Hornung A, Anderer FA, Kieninger $G$. The clinical validity of circulating tumorKieninger G. The clinical validity of circulating tumor-
associated antigens CEA and CA19.9 in primary diagnoassociated antigens CEA and CA19.9 in primary diagno-
sis and follow-up of patients with gastrointestinal sis and follow-up of patients with gastroin

13 Tian F, Appert HE, Myles J, Howard JM. Prognostic value of serum CA19.9 levels in pancreatic adenocarcinoma. Ann Surg 1992; 215: 350-5.

14 Yamaguchi $K$, Enjoji $M$, Tsuneyoshi $M$. Pancreatoduodenal carcinoma: a clinicopathologic study of 304 patients and immunohistochemical observation for CEA and CA19.9. F Surg Oncol 1991; 47: 148-54.

15 Albert MB, Steinberg WM, Henry JP. Elevated serum levels of tumor marker CA19.9 in acute cholangitis. Dig Dis Sci 1988; 33: 1223-5.

16 Benamouzig $R$, Buffet $C$, Fourre $C$, Ink O, Moati F, Etienne JP. Serum levels of carbohydrate antigenic determinant (CA19.9) in obstructive jaundice. Dig Dis Sci 1989; 34: 1640-2.

17 Encabo G, Ruibal A. Seric CA19.9 levels in patients with non tumoral pathologies. Our experiences in 892 cases. Bull Cancer 1986; 73: 256-9.

18 Gupta MK, Arciaga R, Bocci L, Tubbs R, Bukowski R, Deodhar $S$. Measurement of a monoclonal-antibodydefined antigen (CA19.9) in the sera of patients with malignant and nonmalignant diseases. Cancer 1985; 56: malignant

19 Haglund C, Roberts PJ, Jalanko H, Kuusela P. Tumour markers CA19.9 and CA50 in digestive tract malignanmarkers CA19.9 and CA50 in digestive tract
cies. Scand $\mathcal{F}$ Gastroenterol 1992; 27: 169-74.

20 Andriulli A, Gindro T, Piantino P, et al. Prospective evaluation of the diagnostic efficacy of CA19.9 assay as a marker for gastrointestinal cancers. Digestion. 1986; 33: 26-33.

21 Basso D, Fabris C, Del Favero G, et al. How does liver dysfunction influence serum CA19.9 in pancreatic cancer? Ital f Gastroenterol 1990; 22: 1-6.

22 Haglund C, Lindgren J, Roberts PJ, Nordling S. Difference in tissue expression of tumour markers CA19.9 and CA50 in hepatocellular carcinoma and cholangiocarcinoma. in hepatocellular carcinoma

23 Jalanko H, Kuusela P, Roberts P, Sipponen P, Haglund C, Makela O. Comparison of a new tumor marker, CA 19.9, Makela O. Comparison of a new tumor marker, CA 19.9,
with $\alpha$-fetoprotein and carcinoembryonic antigen in with $\alpha$-fetoprotein and carcinoembryonic antigen in patients with upper

24 Putzki H, Ledwoch J, Student A, Jablonski M, Heymann H. Tumor markers carcinoembryonic antigen, tissue polypeptide antigen, and carbohydrate antigen 19.9 in liver diseases. F Surg Oncol 1988; 37: 133-5

25 Atkinson BF, Ernst CS, Herlyn M, Steplewski Z, Sears HF Koprowski $H$. Gastrointestinal cancer-associated antigen in immunoperoxidase assay. Cancer Res 1982; 42: 4820-3. 
26 Bocci V. The role of sialic acid in determining the life-span of circulating cells and glycoproteins. Experientia 1976 32: $135-40$.

27 McFarlane IG. Hepatic clearance of serum glycoproteins. Clin Sci 1983; 64: 127-35.

28 Deugnier Y, Loréal O, Turlin B, et al. Liver pathology in genetic hæmochromatosis: a review of 135 homozygous
cases and their bio-clinical correlations. Gastroenterology 1992; 102: 2050-9.

29 Brissot P, Deugnier Y. Genetic haemochromatosis. In: McIntyre NBJ, Bircher J, Rizzetto M, Rodes J, eds. Oxford textbook of clinical hepatology. Oxford: Oxford Medical, 1991: 948-58.

30 Summers K, Halliday J, Powell L. Identification of homozygous hæmochromatosis subjects by measurement of
biochemical hepatic iron index. Hepatology 1990; 12: bioche 20 .

31 Powell L, Summers K, Board P, Axelsen E, Webb S, Halliday J. Expression of hæmochromatosis in homozygous subjects. Implications for early diagnosis and prevention. Gastroenterology 1990; 98: 1625-32.

32 Deugnier Y, Turlin B, Powell L, et al. Differentiation between heterozygotes and homozygotes in genetic hæmochrom index: a study of 192 cases. Hepatology 1993; 17: 30-4.
33 Barry M, Sherlock S. Measurement of liver-iron concentration in needle-biopsy specimens. Lancet 1971; ii: 100-3. 34 Brissot P, Herry D, Verger J, et al. Assessment of liver iron content in 271 patients: reevaluation of direct and indirect methods. Gastroenterology 1981; 80: 557-65.

35 Paulson JC, Colley KJ. Glycosyltransferases. F Biol Chem 1989; 264: 17615-8.

36 Kim YS, Perdomo J, Whitehead JS, Curtis KJ. Glycosyltransferases in human blood. $\mathcal{F}$ Clin Invest 1972; 51: 2033-9.

37 Guyader D, Zanninelli G, Brissot P. Fer non lié à la transferrine et charge hépatique en fer. Gastroenterol Clin Biol 1992; 16: 756-9.

38 Marshall JS, Green AM, Pensky J, Williams S, Zinn A, Carlson DM. Measurement of circulating desialylated glycoproteins and correlation with hepatocellular damage. glycoproteins and correlation with

39 Marshall JS, Williams S, Jones P, Hepner GW. Serum desialylated glycoprotein in patients with hepatobiliary dysfunction. F Lab Clin Med 1978; 92: 30-7.

40 Sawamura T, Nakada H, Hazama H, Shiozaki Y, Sameshima Y, Tashiro Y. Hyperasialoglycoproteinemia in patients with chronic liver diseases and/or liver cell carcinoma. Gastroenterology 1984; 87: 1217-21.

41 Collazos J. Clinical and laboratory evaluation of CA19.9 in cirrhotic patients. Eur 7 Med 1992; 1: 215-8. 